\title{
Estágios supervisionados e o Programa Institucional de Bolsa de Iniciação à Docência: duas faces da mesma moeda?*
}

\author{
Selma Garrido Pimenta' (D) \\ Maria Socorro Lucena Lima" (D)
}

\section{RESUMO}

O artigo resulta de pesquisa teórica sobre políticas de formação de professores e tem por objetivos analisar as possibilidades e os limites da formação desses profissionais nos cursos de licenciatura e examinar os embates e as contradições da política que opõe o estágio curricular supervisionado ao Programa Institucional de Bolsa de Iniciação à Docência. Como pressupostos teóricos, deve-se considera o professor como intelectual crítico-reflexivo pesquisador da práxis docente e o estágio como atividade teórica na práxis formativa. A análise dos documentos e das produções (teses, dissertações, artigos) que compuseram o corpus da pesquisa evidenciou que o estágio curricular supervisionado e o Programa Institucional de Bolsa de Iniciação à Docência realizados nos mesmos cursos de licenciatura não se juntam em objetivos e atividades comuns para fortalecer uma política de formação docente no país que supere a lógica da formação fragmentada, individualista e competitiva própria das sociedades capitalistas neoliberais.

\section{PALAVRAS-CHAVE}

estágio; práxis docente; política de formação; professor intelectual crítico-reflexivo.

\footnotetext{
*Texto oriundo da Sessão Especial "Políticas Educacionais em disputa e novas legislações na formação de professores", apresentado na $38^{a}$ Reunião Anual da Associação Nacional de Pós-Graduação e Pesquisa em Educação, realizada em São Luiz do Maranhão, MA, em outubro de 2017.

'Universidade de São Paulo, São Paulo, SP, Brasil.

"Universidade Estadual do Ceará, Fortaleza, CE, Brasil.
} 


\title{
SUPERVISED INTERNSHIP AND THE PROGRAMA INSTITUCIONAL DE BOLSA DE INICIAÇÃO À DOCÊNCIA: TWO FACES OF THE SAME COIN?
}

\begin{abstract}
This article is a result of a theoretical research on teacher education programs. Its purpose is to analyze the possibilities and limits during the education of these professionals in teacher education and to analyze the conflicts and contradictions of the policy that opposes the supervised curricular internship to the Programa Institucional de Bolsa de Iniciação à Docência. Theoretical assumptions consider teachers as critical intellectuals/scholars-reflexive researchers of teaching praxis and the internship as a theoretical activity in the teaching education praxis. The analysis of documents and productions that made up the corpus of our research showed that the supervised curricular internship and the Programa Institucional de Bolsa de Iniciação à Docência performed during the same teacher education; they do not work together, not sharing the same objectives and common activities to strengthen national education policies that overcome the logic of a fragmented, individualist and competitive education found in neoliberal and capitalist societies.
\end{abstract}

\section{KEYWORDS}

supervised internship; teaching education praxis; teacher critical intellectual/scholar-reflexive researcher; policy education teacher.

\section{ESTADIOS SUPERVISADOS Y EL PROGRAMA INSTITUCIONAL DE BOLSA DE INICIAÇÃO À DOCÊNCIA: DOS FACES DE LA MISMA MONEDA?}

\section{RESUMEN}

El artículo resulta de una investigación teórica sobre políticas de formación de profesores y objetiva analizar las posibilidades y límites de la formación de esos profesionales en los cursos de licenciatura y analizar los embates y las contradicciones de la política que opone el estadio curricular supervisado al Programa Institucional de Bolsa de Iniciação à Docência. Como presupuestos teóricos, se considera al profesor como intelectual crítico-reflexivo investigador de la praxis docente y las pasantías como actividad teórica en la praxis formativa. El análisis de los documentos y de las producciones (tesis, disertaciones, artículos) que compusieron el corpus de la investigación evidenció que las estadio curricular supervisado y el Programa Institucional de Bolsa de Iniciação à Docência realizados en los mismos cursos de licenciatura, no se unen en objetivos y actividades comunes para fortalecer una política de formación docente en el país que supere la lógica de la formación fragmentada, individualista y competitiva propia de las sociedades capitalistas neoliberales.

PALABRAS CLAVE

prácticas; práxis docente; política de formación; profesor intelectual crítico-reflexivo. 


\section{INTRODUÇÃO}

Entre as políticas de formação de professores implementadas nas reformas da educação nos anos recentes, o Programa Institucional de Bolsa de Iniciação à Docência (PIBID) se instala em forma de atividades e projetos de ensino e pesquisa nos mesmos espaços institucionais por onde transita o estágio curricular supervisionado.

Além das obrigações próprias de seu cotidiano, as escolas públicas têm sido sobrecarregadas com as políticas do ensino fundamental e médio, como a do processo de implementação e operacionalização de avaliações institucionais, com seus alunos sendo comparados e classificados conforme indicadores externos nacionais e internacionais. Nesse contexto, ainda recebem a responsabilidade trazida pela universidade de dar conta de alunos estagiários e de alunos pibidianos, conforme definidos pelo programa criado pela Coordenação de Aperfeiçoamento de Pessoal de Nível Superior (CAPES).

Em busca de espaço para suas atividades, orientadores de estágio e coordenadores do PIBID se colocam na escola. Tal movimento sugere muitas indagações, entre elas: Seria o PIBID um tipo de estágio ideal? Conseguiria substituir o estágio curricular? Conseguiria atribuir bolsas para todos os estudantes de licenciatura? Teria proposituras para se inserir e tornar-se um projeto institucional nas universidades e nas escolas? $\mathrm{Na}$ luta pela formação de qualidade, em que ponto as ações do PIBID e a realidade do estágio curricular, historicamente presente e consolidado, vão se aproximar?

Com atividades de natureza similares, mas com fundamentação e condições diferentes, uma vez que os estágios não têm aporte de verbas, alunos e professores se encontram no mesmo espaço das instituições na busca da formação de novos docentes. Tal movimento sugere muitas indagações, entre elas: PIBID e estágio curricular supervisionado, mesmo ocupando os mesmos espaços pedagógicos, na prática se aproximam em suas ações, de modo que um possa fortalecer o outro no projeto comum da formação de professores? Poderiam ressignificar e apontar possibilidades de se considerar a unidade teoria e prática (práxis) em um projeto que integra as universidades e as escolas públicas?

Pensando nessas questões, o texto se propõe a analisar as possibilidades e os limites da formação de professores nos cursos de licenciatura no panorama de políticas atuais (resolução CNE/CP n. 02/2015, que definiu as Diretrizes Curriculares Nacionais para a formação inicial em nível superior e para a formação continuada); analisar os embates criados pela política que opõe o estágio curricular supervisionado, componente obrigatório do currículo dos cursos de formação de professores, ao PIBID, criado e financiado pelo Ministério da Educação (MEC) por meio da CAPES (Brasil, 2007); e apontar possibilidades para um projeto político pedagógico organicamente articulado para a formação de professores decorrentes dos referidos embates.

\section{A FORMAÇÃO DE PROFESSORES NAS POLÍTICAS PÚBLICAS EM EDUCAÇÃO}

As políticas que interferem nos processos de formação docente no contexto atual são decorrentes de um processo de mercantilização da educação como parte 
do elenco das novas estratégias de desenvolvimento sustentável e de crescimento econômico defendidas pelo Banco Mundial na área educacional brasileira. Essas estratégias, em países como o Brasil, eximem cada vez mais a participação do Estado nos serviços educacionais e determinam as diretrizes para a educação ao mesmo tempo em que financiam projetos que têm como foco o combate à pobreza.

No contexto da crise mundial da economia na década de 1980, a instauração do Estado avaliador (expressão de Neave, 1988 apud Yannoulas, Souza e Assis, 2009, p.59) se configurou como exemplo de política para desobrigar a participação direta dos Estados nos serviços educacionais. Ao mesmo tempo, esse modelo de gestão pública se constituiu como incentivo à meritocracia no âmbito das instituições educacionais e entre os professores.

Para Dias Sobrinho (2004, p. 708), o Estado avaliador "intervém para assegurar mais eficiência e manter o controle daquilo que considera ser qualidade". Em suas palavras, "na educação superior tornou-se obrigatório o aumento da eficiência de acordo com a fórmula: produzir mais, com menos gastos". Nessa economia de predominância financeira são anuladas as fronteiras entre o público e o privado, o que promove, conforme Sguissardi (2015), uma educação superior desigual, com baixa qualificação para a maioria da população e alta qualificação para aqueles da elite.

Nesse cenário, de acordo com Schneider e Rostirola (2015, p. 496), a avaliação educacional

[...] representa uma estratégia de governação em que o Estado atua a partir dos resultados obtidos em testes organizados e realizados, primeiramente, pelo próprio país e, num segundo momento, por agências multilaterais. Tem a ver, portanto, com o fortalecimento de referenciais neoliberais, representados pela adesão a medidas políticas e administrativas ajustadas às leis do mercado e pela sofisticação dos mecanismos de controle e responsabilização dos resultados obtidos pelos sistemas educacionais.

As prioridades das políticas neoliberais incidem negativamente sobre a formação de professores ao acentuar práticas de ensinar em detrimento de teorias e implementar sistemas de avaliação e premiação que precarizam o trabalho docente, instituindo bônus no lugar de aumento salarial. Essas e outras medidas somadas a tantas mais passam pela vida profissional dos professores sem que eles compreendam com clareza os determinantes e a intencionalidade de tais ações.

Firma-se, cada vez mais, o empenho pelas avaliações externas das escolas, que as classificam de acordo com critérios que não condizem com a realidade do seu coletivo institucional.

Esse panorama, decorrente de acordos internacionais expressos nas políticas de educação, interfere nos processos de formação docente nos quais estão situadas a didática e a prática de ensino como mediadoras da ação formativa dos cursos de magistério e no trabalho do professor. Inclui-se, nesse contexto, o modelo de educação para o século XXI delineado pela Organização das Nações Unidas para a Educação, a Ciência e a Cultura (UNESCO), legitimado no Relatório Delors desde os anos de 1990. Tais decisões passaram a ser fundamentais para as políticas 
em educação tomando como base as ideias de globalização, cujo discurso gravita em torno da órbita da necessidade de "mundializar a cultura, a adaptação às tecnologias da informação, de forma a primar pela cooperação e solidariedade, a paz e a justiça social" (Shiroma, Moraes e Evangelista, 2000, p. 13).

O ensino superior, nessa perspectiva, enquadra-se na categoria de motor do desenvolvimento econômico, enquanto o professor passa a ser considerado um agente de mudanças, com formação para a pesquisa e capacidade de organização e sociabilidade, a fim de garantir a sobrevivência de valores e a promoção de mudanças na sociedade globalizada. Assim, as práticas de gestão empresarial infiltram-se como tendência administrativa e tornam-se evidentes no movimento de espaços transformados em centros de excelência e na primazia da produtividade acadêmica dos professores. A difusão desse tipo de concepção conduz à ampliação desmedida do mercado consumidor de "bens e serviços", do qual o ensino superior faz parte.

As chances de extrair lucro da desqualificação dos trabalhadores, advinda de uma formação sucateada, abrem oportunidade de negócio para os empresários da educação. A situação de instabilidade, precarização, terceirização e vulnerabilidade a que os educadores estão expostos aumenta o mercado de venda de consultorias, de certificação e promessas de empregabilidade. Nas palavras de Shiroma, Moraes e Evangelista (2000, p. 13, grifos do original), "a escola que, na origem grega, designava o lugar do ócio, é transformada em um grande negócio".

Zeichner (2013) mostra que na sociedade globalizada as políticas educacionais, incluindo as de formação de professores, não são idealizadas em seus países de origem, mas nos polos centrais da economia, como os Estados Unidos. A repercussão desse fato nas práticas dos professores e no cotidiano escolar mostra a marca da mercantilização, das políticas de educação e da lógica de livre mercado. Tais direcionamentos resultam no desmantelamento da formação universitária, alargando as desigualdades no campo da educação. Do mesmo modo, editores vendem ao governo pacotes de testes padronizados, de programas, projetos e materiais didáticos, o que implica a tentativa de desprofissionalização do magistério, que corre por fora do sistema formal de ensino superior, acompanhado pelo discurso de exaltação da prática.

Tomando como base essas considerações de Zeichner (2013), parece-nos que o PIBID seria um exemplo desses pacotes, na medida em que, criado inicialmente como exclusivo para as universidades públicas (edital de 2007), abriu-se para as instituições particulares filantrópicas, sem fins lucrativos (Pontifícia Universidade Católica - PUC, e comunitárias), e no edital de 2013 abriu-se para as instituições particulares financistas, que têm no segmento da licenciatura um promissor mercado.

Zeichner (2013) complementa seu pensamento com uma abordagem crítica sobre as políticas de internacionalização que envidam esforços na preparação de professores na direção de uma economia global e destaca, nesse contexto, a tendência em seu país, Estados Unidos, de formar professores em instituições e grupos associados fora do sistema de ensino superior. Em suas palavras: 
Não há razão para acreditar, em função do fracasso das experiências de desregulamentação e da lógica de livre mercado, que a tendência atual para desmantelar a formação universitária de professores e substituí-la por uma lógica de economia de livre mercado resultará em algo positivo para a nação. Continuar nesse caminho servirá apenas para ampliar as desigualdades que existem atualmente entre diferentes segmentos da população e da educação pública. (Zeichner, 2013, p. 42)

O enfoque para a ampliação da desigualdade na formação de professores e os danos causados na educação nos levam a verificar que, mesmo no interior da formação realizada pela universidade pública, gratuita e de qualidade, tão defendida por nós, são gerados distintos tipos de formação para o mesmo diploma de conclusão de curso. Os alunos trabalhadores são os mais prejudicados, uma vez que não dispõem de tempo para a participação em projetos e programas de pesquisa e docência. Ao mesmo tempo em que critica a formação de professores, nos moldes da sociedade globalizada, Zeichner (2013) aponta para uma educação global crítica, que objetiva ajudar os professores na compreensão da realidade em que estão inseridos e os incentiva na participação nas lutas por justiça social.

Distante dessa proposta colaborativa, avançam os processos de precarização da escola e das universidades públicas, inclusive no âmbito da pós-graduação (Peixoto, 2009; Robertson, 2009; Sguissardi, 2008). Essa última, mergulhada em procedimentos competitivos de produtividade cumulativa, parece afastar-se cada vez mais dos processos reflexivos e problematizadores próprios da pesquisa, que poderiam viabilizar a compreensão da realidade. A esses problemas da formação pós-graduada no contexto das políticas privatistas e mercantis acrescentamos a institucionalização dos mestrados profissionais, que na área da educação se voltam à valorização das práticas sem a fertilização que as teorias propiciam, e a pesquisa fica reduzida a simples estudos.

Concordamos com Saviani (2008), quando nos ensina que a função mediadora da educação no contexto social precisa ser analisada com substrato na problematização das questões advindas da prática social, instrumentalizada por teorias que auxiliem na compreensão crítica dessa realidade e tendo como horizonte a viabilidade da sua incorporação na vida dos alunos.

Uma das preocupações do contexto em que a educação está inserida é o investimento em políticas focais de curto alcance. Conforme Sguissardi (2015, p. 869):

Constata-se que o Estado, tendo ideológica e operacionalmente dificuldade de apostar no investimento maciço na educação superior, tem buscado, via políticas focais de curto alcance - Prouni e Fies, em especial - garantias de alguma igualdade de condições de acesso, mas que não preveem igualdade de condições de permanência e de sucesso no mercado de trabalho.

A análise do autor nos permite apontar que o PIBID também se configura como uma política focal de curto alcance, uma vez que é destinado à pequena parcela de estudantes que cursam a licenciatura, como analisaremos nos itens a seguir. 


\section{O PROGRAMA INSTITUCIONAL DE BOLSA DE INICIAÇÃO À DOCÊNCIA E A FORMAÇÃO DE PROFESSORES}

Apesar de não se definir como um estágio, tivemos nos anos recentes a criação do PIBID, que transita nos mesmos espaços institucionais em que se aplica a atuação dos estagiários.

O PIBID é um programa criado e financiado pelo MEC por meio da CAPES, instituído com a portaria normativa n. 38, de 12 de dezembro de 2007, na gestão do presidente Lula e do ministro da Educação Fernando Haddad, ambos do Partido dos Trabalhadores (PT), com a finalidade de valorizar o magistério e apoiar estudantes de licenciatura plena. Apesar de ter sido lançado em dezembro de 2007, as atividades relativas ao primeiro edital somente se iniciaram nos primeiros meses de 2009. Atualmente, a estrutura e funcionamento do PIBID são regulamentados pela portaria n. 096, de 18 de julho de 2013, da CAPES.

Apresenta como objetivos principais unir as secretarias estaduais e municipais de educação e as universidades públicas a favor da melhoria das escolas públicas e o incentivo à carreira do magistério, contribuindo para o aperfeiçoamento da formação de docentes em nível superior (Brasil, 2010). Além desses, pretende também contribuir para que os estudantes de licenciatura se insiram na cultura escolar do magistério por meio da apropriação e da reflexão sobre instrumentos, saberes e peculiaridades do trabalho docente (CAPES, 2013, p. 2-3). Oferta bolsas de estudo para os professores coordenadores das universidades, para professores supervisores da escola pública da educação básica que recebem os licenciandos e para os estudantes em formação dos cursos de licenciatura. As bolsas são atribuídas somente aos participantes do programa, o que exclui a maioria dos estudantes de licenciaturas, uma vez que o número de bolsas é limitado. Dados divulgados pela CAPES (2013) mostram que apenas 5,38\% dos estudantes matriculados em cursos de licenciatura no país foram contemplados com o PIBID.

$O$ registro da intencionalidade do PIBID, também demonstrado por pesquisas sobre o tema (Encontro Nacional de Didática e Práticas de Ensino - ENDIPEs, 2012/2014/2016 e divulgados no portal da CAPES), é louvável, no sentido de pretender incentivar, valorizar e elevar a qualidade da formação dos alunos de licenciaturas que participam do programa. Positiva também é a proposta de integração com a escola no intuito de inserir o bolsista no cotidiano das instituições. Como programa que se propõe inovador, tem potencial de mobilizar os docentes comprometidos e os estudantes envolvidos na busca de melhorias nos espaços onde se localizam, para o que concorre como fator estimulante a oferta de bolsas.

Em sua tese de doutoramento, Gimenes (2016) apresenta um estudo sobre os editais do PIBID, o que permite verificar sua trajetória legal e conceitual. No ato legal de sua criação (edital MEC/CAPES/FNDE n. 01/2007), o programa foi definido para as instituições federais de ensino superior e universidades; já no edital CAPES n. 02/2009, o programa foi ampliado para as instituições estaduais de ensino superior; em 2010, para instituições públicas municipais e comunitárias, confessionais e filantrópicas sem fins lucrativos, além das que trabalhavam nos programas de formação de professores (Programa de Apoio à Formação Superior e 
Licenciaturas Interculturais Indígenas - Prolind; e Programa de Apoio à Formação Superior em Licenciatura em Educação do Campo - Procampo), editais n. 18 e n. 2/2010, este em conjunto com a Secretaria de Educação Continuada, Alfabetização e Diversidade (SECAD), e para instituições públicas de ensino superior (IPES), em 2011. Em 2013, foi instituído o PIBID Diversidade (edital n. 66/13). E nesse mesmo ano, com o edital n. 61/2013, o programa fora destinado a todas as instituições privadas com bolsistas do Programa Universidade para Todos (ProUni). Um dos pontos considerados mais problemáticos do programa foi a inclusão das instituições privadas de ensino superior. Se considerarmos que a maioria dessas instituições conta com verbas do ProUni, e que muitas delas dependem disso, o PIBID com a atribuição de bolsas passou a ser mais um caminho de escoamento de recursos públicos. Dos ingressantes, em 2013, em cursos de licenciatura no país, as instituições privadas responderam por $68 \%$ de matriculados, sendo 88\% destes na modalidade Educação a Distância (EaD) (INEP, 2014). Se lembrarmos de que entre essas instituições a maioria são financistas, que vêm comprando as instituições menores, formando conglomerados privatistas, que contam com capital internacional e cujos lucros em 2015/2016 foram superiores aos do sistema bancário, pode-se perceber que o PIBID acabou por ser, de fato, um programa de repasse de recursos públicos para as instituições financistas, contrariando claramente seus objetivos de melhoria da formação de professores para as escolas públicas.

Em sua pesquisa, Gimenes (2016) evidencia como um dos pontos questionáveis na trajetória dos editais do programa a inclusão das instituições privadas:

É interessante observar como as instituições privadas com e sem fins lucrativos vão [foram] ganhando espaço no desenvolvimento histórico do PIBID, autorizadas a participar do Programa a partir de 2013, em 2014 essas instituições recebem 18\% das concessões desse Programa e representam 47\% das IESs parceiras. (Gimenes, 2016, p. 123)

No entanto, apesar dessa perversão das finalidades do programa, é importante lembrar que o PIBID teve adesão crescente pelos sujeitos envolvidos que buscaram afirmá-lo como uma política de Estado de formação pública de professores.

Gimenes (2016, p. 124-125) problematiza essa questão:

[...] nos parece precipitado afirmar que esse Programa esteja consolidado como política de Estado, uma vez que os verbos utilizados na alteração da LDB 9.394/96 bem como no PNE 2014-2024 são fracos, pois indicam que o PIBID deve ser incentivado e aumentado, não havendo obrigatoriedade a esse compromisso. O Programa fica, portanto, condicionado à disponibilidade orçamentária e financeira da Capes, conforme Portaria 096/2013 da Capes.

A autora lembra, ainda, que a ampliação do PIBID não conseguiu a legitimidade que o tornasse obrigatório, ficando à mercê da disponibilidade da CAPES, sujeito às verbas e/ou às vontades políticas dos governantes que assumem o poder. 
Apesar de ser reconhecido positivamente pelos sujeitos que dele participam, o PIBID tem um caráter transitório. Cabe então indagar até que ponto o programa conseguiu formar um pensamento crítico-reflexivo propositivo em seus participantes. Parece que a sua transitoriedade está sendo evidenciada pelas políticas de exclusão social que o Governo Temer vem definindo a partir de 2016 - no caso do PIBID, os cortes orçamentários para a educação, por exemplo, significaram a redução de bolsas do programa já em 2017.

Entretanto, o PIBID propiciou uma produção interessante e fértil de pesquisas, estudos e publicações sobre o tema da formação de professores. Entre os temas surgidos, o que nos parece central é a da relação entre as universidades e as escolas públicas enquanto campos de estágio privilegiado pelo programa. No entanto, os estudos também mostram seus limites e suas contradições.

Em estudo realizado por Gimenes e Pimenta (2013), O que dizem as publicações sobre o PIBID no Encontro Nacional de Didática e Práticas de Ensino (ENDIPE) periodo 2008 a 2012? , as autoras analisam os 64 trabalhos publicados nesse evento no período demarcado e concluem que em $81 \%$ das publicações fica evidente o tom de otimismo em relação à novidade que é o PIBID. A articulação entre universidade e escola e a possibilidade de articulação entre teoria e prática são os principais motivos para o otimismo em relação a esse programa. Em um dos artigos analisados, Carneiro (2012) destaca o sentimento expressado pelos participantes do programa de que é possível a renovação de metodologias de ensino e o despertar para práticas docentes mais inovadoras e dinâmicas a partir da troca de experiências entre a escola e a universidade (Gimenes, 2016, p. 8-9).

No estudo sobre as pesquisas, no entanto, Gimenes e Pimenta (2013) destacam alguns silêncios sobre temas que poderão aprofundar as análises, por exemplo: O que pensam os alunos das licenciaturas sobre a dualidade estágio $x$ PIBID? Como os docentes (não pibidianos) avaliam o programa em suas escolas? E os professores das escolas que recebem estagiários e não recebem bolsa? Os pibidianos se inseriram profissionalmente? Onde? Em escolas públicas?

Ao atribuir a prerrogativa de articulação entre escola e universidade e de valorização da formação de professores para o PIBID e com o relativo sucesso da proposta, aponta Gimenes (2016, p. 112) que “[...] temos como uma das consequências o silenciamento dos estágios e das próprias licenciaturas nas discussões sobre formação de professores. Assim, a parte é elevada ao todo, e a totalidade é desfocada".

Enquanto programa, o PIBID é efêmero, não está enraizado na política pública, o que pode ser constatado com a sua redução a partir de 2017, fato que tem gerado um sentimento de desilusão. Isso nos permite questionar se o PIBID verdadeiramente estaria valorizando a docência e a pesquisa sobre ela, aspectos até então propalados nos discursos de alguns acadêmicos e de gestores oficiais do programa.

Considerando as questionáveis condições de trabalho dos professores de estágio e as favoráveis condições do PIBID, Gimenes (2016, p. 112) também evidencia que o programa tem sido considerado em si mesmo apartado dos estágios e dos demais componentes curriculares do curso de formação. Examinando as condições favoráveis com verbas específicas, o que não se faz presente nos estágios 
e demais atividades do curso, é lícito afirmar que o programa vem constituindo-se como um prejuízo para estes.

Em contrapartida, a polaridade entre PIBID e estágio que tem sido acentuada pelos gestores oficiais, pelas universidades, e mesmo nas escolas, fere o coletivo do corpo docente estabelecendo, com disparidade, tratamentos diferentes e aulas individuais em que o grupo de estágio sempre sai perdendo.

\section{O ESTÁGIO SUPERVISIONADO NA FORMAÇÃO DE PROFESSORES: PROJETOS EM CONFRONTO}

Para tratar do estágio na formação de professores, partimos da concepção por nós defendida de que o professor é um profissional crítico-reflexivo e pesquisador de sua práxis e da práxis educativa que realiza na escola em que atua (Ghedin, 2002; Ghedin, Oliveira e Almeida, 2015; Pimenta, 2012; Pimenta e Anastasiou, 2002). Esse professor também é um profissional com sólida formação teórica, compromisso e sensibilidade social e humana com vistas a contribuir na superação das desigualdades educacionais. Possui uma formação consistente, que respalda os futuros docentes para o enfrentamento coletivo dos desafios próprios da práxis coletivamente vivenciada em contextos, cooperando para que aprendam a analisar, compreender e criar procedimentos de ensino que assegurem aprendizagens emancipatórias. Além disso, esse professor é atuante para reivindicar as condições de trabalho necessárias a essas finalidades, como estatuto profissional, quadro de carreira, ingresso por concurso, permanência e salários dignos. É essa concepção que predomina no meio acadêmico de ensino e pesquisa das instituições públicas.

Em contraposição, apresenta-se a concepção tecnicista do professor, que predomina nas instituições privadas financistas. Essa concepção entende o professor como um técnico prático, com identidade frágil, executor dos scripts produzidos por agentes externos (empresários/financistas do ensino). Assim, a docência é reduzida a habilidades instrumentais e a saberes práticos, sem "teoria". Nessa perspectiva, o estatuto profissional é precário, com profissionais contratados por tempo determinado, sem direitos trabalhistas. Essa concepção predomina no setor privado mercadológico, que domina a formação presencial e a $\mathrm{EaD}$ no Brasil: $68 \%$ das matrículas nos cursos de licenciaturas, e destes, $88 \%$ em EaD (INEP, 2014).

O estágio configurado como espaço de pesquisa nos cursos de formação, além de contribuir para a construção da identidade docente, amplia e aprofunda o conhecimento pedagógico e da práxis educativa docente, especialmente quando se vincula às escolas públicas (Pimenta e Lima, 2004). Os estudos sobre os cursos de licenciatura têm evidenciado, no entanto, que nem sempre coordenadores, professores e alunos percebem esse valor formativo como oportunidade de ir além e de superar uma simples observação, participação e regência na sala de aula. E cabe indagar até que ponto a escola tem sido um espaço de questionamento, investigação, sistematização e produção de conhecimentos decorrentes da reflexão sobre a sua realidade, sobre si mesma e sobre o ensino que nela se realiza?

Considerando que o estágio é uma atividade teórica instrumentalizada da práxis (Pimenta, 2012), e uma atividade curricular obrigatória, registrada na vida 
escolar dos alunos, seu exercício é marcado pelo compromisso de integração entre a escola e a universidade. A reflexão sobre a práxis docente é um significativo componente do campo epistemológico da didática e requer estudos e análises teóricas. $\mathrm{O}$ estágio possui características que podem subsidiar a reflexão sobre a prática. $\mathrm{O}$ fato de ter como campo de conhecimento as pesquisas nas áreas da pedagogia e da didática, a relação ensino e pesquisa configura-se na medida em que se ensina e se aprende. Assim, concordamos com Freire (1996, p. 32) ao afirmar que não há ensino sem pesquisa, nem pesquisa sem ensino.

Sobre a necessidade de teorização das atividades de estágio, Zabalza (2014, p. 29) afirma sua importância na estrutura curricular sempre com respaldo em fundamentação teórica que sustente sua prática:

[...] o estágio constitui um cenário formativo no qual se entrecruzam muitos dos elementos e desafios a serem enfrentados pelo Ensino Superior [...] de qualidade de ensino. Os desafios são [...] grandes e para fundamentá-los [...] é preciso dotar o estágio de um discurso teórico que acabe aglutinando seu papel nas exigências formativas que a sociedade moderna propõe a seus jovens por meio da universidade.

Para nós (Pimenta et al., 2018), o estágio curricular supervisionado contribui para a desconstrução de mitos e preconceitos ao possibilitar que os estudantes tenham seu olhar instrumentalizado com teorias que lhes permitam uma análise crítica fundamentada das situações do ensino em seus contextos. No entanto, a necessária articulação entre as universidades e a escola-campo de atuação agrava-se diante da proliferação do PIBID em cursos de licenciatura que muitas vezes superlotam as escolas da educação básica sem o devido planejamento participativo, orientação e acompanhamento por parte das unidades de ensino superior e dos professores supervisores. De acordo com Eugênio (2015), o estágio carece de ações interativas da instituição formadora com a escola recebedora, bem como de alargamento de espaços de atuação, transportados à sala de aula. Os professores que recebem estagiários acrescentam às suas tarefas diárias a incumbência de receber as equipes e alocá-las em seu espaço de trabalho. A rotatividade de estagiários mistura-se com a rotina da sala de aula, que por sua vez já tem em seu cotidiano inúmeros desafios a serem superados.

Os estudos de Romanowski e Martins (2015) revelam o desafio de ter a prática docente como espaço de problematização na escola básica ao evidenciar as contradições ali existentes e propõem:

[...] ultrapassar o eixo epistemológico da teoria como guia da ação predominante na organização curricular dos cursos de Licenciatura e trabalhar com a concepção de teoria como expressão da prática. Fazer do campo da Educação Básica um espaço de problematização, análise crítica e sistematização dos conhecimentos produzidos por seus agentes no enfrentamento dos problemas decorrentes da contradição que persiste entre a formação acadêmica recebida e a realidade da escola onde atuam. (Romanowski e Martins, 2015, p. 151) 
Trabalhar a teoria como expressão da prática e fazer desta um espaço de problematização é um desafio a ser defendido e conquistado, conforme afirmam as autoras. Essa postura reflexiva nem sempre se encontra nos cursos de formação de professores. Na maioria deles, há profunda dicotomia entre as disciplinas pedagógicas e as áreas específicas.

Pimenta (2012) ressalta sobre a necessidade de ressignificação da didática e das metodologias ou práticas específicas entendendo que ambas têm o ensino como objeto de estudo. A didática estuda os temas que se referem à relação professor-aluno-conhecimento; às relações de poder, de autoridade e de autoritarismo presentes na escola e na sala de aula e nos sistemas de ensino; ao currículo, projeto político pedagógico e à avaliação necessária; ao trabalho e à atividade docente; à escola existente e a que se deseja e a tantos outros assuntos que determinam, atravessam e dialogam com os das disciplinas específicas.

Nessa perspectiva, é necessário que se considere a análise das condições de trabalho do professor de estágio supervisionado para dar conta de um trabalho de tal complexidade. A falta de um projeto de integração entre os componentes curriculares, de diálogo entre universidade e escola, dificulta ou muitas vezes impede a práxis formativa.

\section{O PROGRAMA INSTITUCIONAL DE BOLSA DE INICIAÇÃO À DOCÊNCIA E O ESTÁGIO SUPERVISIONADO: ENCONTROS E DESENCONTROS}

As análises que empreendemos acerca do PIBID e dos estágios curriculares no contexto das políticas de privatização/mercantilização da educação em nosso país (Sguissardi, 2008) nos permitiram evidenciar contradições, confrontos e desencontros nos cursos de formação inicial de professores. Mas também, atentas às pesquisas e aos movimentos que geraram, essas mesmas análises nos permitiram evidenciar encontros e ressignificações possíveis com vistas à realização do ideal de emancipação humana a que nos propomos.

E o que descobrimos?

O PIBID oferta bolsas para os professores coordenadores das universidades, para os professores supervisores da escola pública da educação básica que recebem os licenciandos e para os estudantes em formação dos cursos de licenciatura participantes do programa, que curiosamente passaram a ser denominados de alunos pibidianos. Sendo as bolsas atribuídas somente aos participantes do programa, a maioria dos estudantes de licenciaturas é excluída, uma vez que o número de ofertas é limitado. Os dados de 2013, divulgados pela CAPES e comparados ao total de estudantes das licenciaturas nesse mesmo ano, mostram que apenas 5,38\% dos estudantes matriculados em cursos de licenciatura no país foram contemplados com o PIBID.

Essa situação, de acordo com Lima (2012), contribui para aprofundar a distância que separa os alunos em formação (futuros professores que deveriam ser titulados pela universidade pública e de qualidade para todos), criando diferentes grupos de licenciandos em uma mesma turma e instituição. Em re- 
latos de docentes de vários cursos de licenciatura de uma mesma instituição foi possível verificar a presença dessa disparidade em suas salas de aula, e também em experiências por nós vivenciadas em nossas turmas de didática, quando constatamos, por exemplo, que em uma classe com trinta e cinco alunos, apenas cinco eram bolsistas do PIBID, e esses mesmos alunos tinham também a bolsa do Programa Institucional de Bolsas de Iniciação Científica (PIBIC). Daí a pergunta que não quer calar: $\mathrm{O}$ que fazer com os trinta sobrantes para garantir uma formação de qualidade para todos? O PIBID em relação ao estágio, mesmo que aparentemente sejam propostas semelhantes, pertencem a campos de poder, estrutura, funcionamento e condições objetivas diferentes.

Enquanto o PIBID se movimenta pelo incentivo das bolsas, direcionadas a coordenadores, alunos e professores da escola recebedora, o estágio é mobilizado pela obrigatoriedade da legislação curricular. As ações formativas no contexto da instabilidade das políticas de formação de professores perdem-se na dispersão de programações que não se encontram em torno de um projeto político pedagógico comum, no qual fosse possível encontrar o espaço formativo das disciplinas de fundamentos pedagógi$\cos$ - didática e metodologias de ensino, ou didáticas específicas - e das disciplinas de fundamentos da educação, articuladas e integradas pelo estágio supervisionado. Um projeto que teria a realidade das escolas públicas como ponto de partida e ponto de chegada da formação; mediadas pela pesquisa como método de conhecimento, análise e compreensão da realidade das escolas situadas em seus contextos, dos problemas e das contradições que a práxis educativa revela. E para que esses estudantes, quando nelas se inserirem como profissionais, sejam capazes de propor e alterar as condições que impedem que a escola cumpra sua finalidade social e política.

Mesmo nos caminhos mais sofridos do seu percurso, o estágio supervisionado mostra ser mais abrangente que o PIBID, uma vez que aponta para a compreensão das contradições, das possibilidades e dos limites de uma escola pública dialeticamente situada. Além disso, o estágio, ao longo de sua história na estrutura curricular nas licenciaturas, evoluiu de uma perspectiva que o situava no final e como a parte prática dos cursos para a sua compreensão como uma atividade teórica que aproxima os estudantes, por meio da pesquisa, da realidade das escolas desde o início do curso (Pimenta e Anastasiou, 2002).

Ainda assim, essa perspectiva transformadora ainda não é encontrada nas práticas pedagógicas e nos projetos e atividades dos cursos de licenciatura em geral. Nesse sentido, considerando as condições institucionais precárias em que os estágios e as disciplinas voltadas às práticas de ensino são desenvolvidas, como aponta Gimenes (2016), citando Lima (2012), o PIBID, permanecendo como privilégio de poucos, poderá desmotivar o conjunto dos docentes para o trabalhar com as licenciaturas. Nessa mesma direção, Freitas (2013, p. 9, grifos nossos) afirma:

Tratar de destinação específica de recursos para determinados e restritos projetos a professores e estudantes nas condições atuais de organização curricular e institucional de grande parte de nossas licenciaturas, significa estabelecer premiação de caráter individual e não consolidar uma política institucional de valorização das licenciaturas. 
Além do caráter individualista e de competitividade que o programa tem provocado, a autora reitera que com esses procedimentos administrativos (referindo-se à definição de programas pontuais, com recursos para projetos restritos) o poder público não consolida uma política nacional de valorização das licenciaturas. Para uma possível superação desses problemas, Gimenes (2016) aponta para a necessidade de um projeto coletivo que envolva as escolas, a universidade e a comunidade configurando uma formação de professores compartilhada entre essas três instâncias formativas. Experiências nessa direção têm sido empreendidas em diferentes países (Zeichner, 2013).

O diálogo entre a universidade e a escola de ensino fundamental e médio vem historicamente tentando acompanhar as mudanças no campo da educação. O encontro com o PIBID nos mesmos espaços, nos últimos anos, no chão da escola de educação básica, nos remete a uma reflexão sobre os respectivos papéis de estágio e PIBID, das possibilidades formativas de ambos e da influência das atividades de um sobre o outro: Em que divergem? Em que ponto poderiam se encontrar?

Por se tratar de formação de professores na licenciatura, iniciamos pelo estudo do contexto da formação de professores nas políticas de educação, que têm recebido influência dos acordos internacionais nos quais a mercantilização e a meritocracia se fazem presentes no cotidiano escolar.

Escola e universidade sofrem os reflexos dessas mudanças na precarização e na ampliação das desigualdades, comprometendo a função mediadora da educação no contexto social.

O estágio supervisionado, situado nas práticas de ensino da estrutura curricular, também se ressente dessas mudanças, que se agravam diante das contradições trazidas pelas atividades do PIBID nos mesmos espaços da escola. Dessa forma, destacamos algumas das principais conclusões de nossas análises:

- O estágio tem compromisso com a práxis docente, como espaço de problematização das contradições existentes em busca da sistematização dos conhecimentos produzidos.

- O PIBID não se enraíza nos cursos de licenciatura na perspectiva de fortalecer seu projeto político-pedagógico em seu todo; ao contrário, cria castas ou grupos diferenciados de licenciandos em uma mesma instituição, favorecendo entre eles a competitividade tão própria das políticas neoliberais, oposta à natureza do trabalho pedagógico educativo dos professores e das escolas.

- A presença e a valorização financeira do PIBID possibilitaram que ficassem evidentes as fragilidades no campo do estágio, que não recebe verbas, e suas próprias fragilidades, cujo orçamento vem sofrendo profundas reduções no Governo Temer.

- O financiamento ao programa vem sendo reduzido a ponto de algumas instituições terem sido dele excluídas, em consequência dos cortes orçamentários sofridos pela CAPES em 2017.

- Esses cortes vêm sendo praticados, apesar do esforço despendido pelos acadêmicos participantes do PIBID que evidenciaram em seus estudos 
e pesquisas os benefícios do projeto e seu potencial para melhorar os cursos de licenciatura em seu todo.

- Em contrapartida, destaque-se a valorização à iniciação à docência provavelmente inspirada na experiência do PIBID, contida na resolução CNE/CP n. 02/2015, que definiu as Diretrizes Curriculares Nacionais para a formação inicial em nível superior e para a formação continuada (item d, 2.3.1) - como uma das atividades teórico-práticas a serem realizadas entre as 200 horas destinadas a outras atividades no currículo dos cursos, como monitoria, extensão, iniciação científica.

- Entre a formação que se efetiva como privilégio de alguns e a formação precarizada, o estágio e o PIBID compõem um projeto de formação que não contempla o coletivo e fere a totalidade de um projeto político-pedagógico de formação docente, o que evidencia a formação de professores no país como uma política frágil e de desqualificação, apesar da tênue inserção da iniciação à docência na citada resolução.

E o que é possível propor?

Tendo como base as contradições apontadas, as experiências em diversas instituições formadoras e os avanços contidos na resolução CNE/CP n. 02/2015 no que se refere ao tema em pauta, apresentamos três propostas aos cursos de licenciaturas, alicerçadas em nossas pesquisas e em autores de todo o país (Pimenta e Lima, 2004): considerar o estágio como eixo articulador de todo o curso, a partir do primeiro semestre; considerar 800 horas para os estágios curriculares somando suas 400 horas definidas nas diretrizes curriculares nacionais n. $02 / 2015$, com as 400 horas definidas para a prática como componente curricular; e considerar a escola pública como o espaço primeiro e privilegiado para a realização dos estágios curriculares.

Com vistas a consolidar as licenciaturas, propomos que o estágio curricular se constitua como eixo articulador do projeto político pedagógico dos cursos, articulando as disciplinas e as atividades tradicionalmente denominadas práticas $\mathrm{e}$ teóricas do currículo. Propomos também que o curso tenha como referência para formação de professores a escola pública. Assim, entendemos que o curso assumirá sua finalidade de instrumentalizar teórica e praticamente a práxis educativa e docente dos futuros professores.

Para que essas propostas sejam compreendidas, apresentamos, ainda que brevemente, os dois principais conceitos que as sustentam: práxis e estágio como práxis formativa.

O conceito de práxis que assumimos sustenta que o conhecimento se dá efetivamente na e pela práxis; a práxis é a atitude (téorica e prática) humana de transformação da natureza e da sociedade. Não basta conhecer e interpretar o mundo teoricamente, é preciso transformá-lo (práxis). Conforme Vázquez (1968, p. 117), a relação teoria e práxis é teórica e prática, na medida em que a teoria, como guia da ação, molda a atividade humana, particularmente a atividade revolucionária; e teórica, na medida em que essa relação é consciente, pensada criticamente, refletida. É a atividade teórica que possibilita que se estabeleça de modo indissociável 
o conhecimento crítico da realidade e o estabelecimento de finalidades políticas de transformação. Mas a atividade teórica não transforma a realidade, ela permite sentidos e significados para essa transformação que só se dá na práxis, ou seja, na ação dos sujeitos historicamente situados.

Nas palavras de Konder (1992, p. 115)

A práxis é a atividade concreta pela qual os sujeitos humanos se afirmam no mundo, modificando a realidade objetiva e, para poderem alterá-la, transformando-se a si mesmos. É a ação que, para se aprofundar de maneira mais consequente, precisa da teoria; é a teoria que remete à ação, que enfrenta o desafio de verificar seus acertos e desacertos, cotejando-os com a prática.

Em seu texto, Frigotto (1990, p. 81) reitera a práxis como a "unidade indissolúvel de duas dimensões distintas no processo de conhecimento: a teoria e a ação. A reflexão teórica sobre a realidade não é uma reflexão diletante, mas uma reflexão em função da ação para transformar a realidade".

Essa compreensão da unidade teoria e prática nos permite afirmar que os estágios nos cursos de formação de professores podem constituir-se como atividade teórica que possibilita a seus estudantes, em sua futura práxis docente, transformarem a realidade do ensino nos contextos em que se situarem, contribuindo para a emancipação humana, conforme Freire (1979) e Franco e Pimenta (2016).

Assim, entendemos que o estágio não é a práxis dos estudantes nos cursos de licenciatura, mas que nesse processo formativo ele se constitui em uma atividade teórica de conhecimento da práxis de ensinar realizada pelos docentes nas escolas. Uma atividade teórica formativa para a qual convergem os demais componentes teóricos do currículo. Nesse sentido, o estágio se constitui em eixo central e articulador do curso desde o seu início, com a finalidade de instrumentalizar teoricamente os estudantes estagiários para realizarem constantes leituras, análises e perceber as problematizações da práxis educativa que ocorrem nas escolas, nas salas de aula, nas atividades curriculares que são realizadas pelos educadores nas escolas públicas, com a finalidade de que em sua atuação eles possam colaborar para as transformações necessárias para assegurar a emancipação humana e social de seus alunos, em sua atividade própria de ensinagem (Pimenta e Anastasiou, 2002).

E por que centrar o estágio curricular na escola pública? Se não por outra razão, porque nela está concentrada cerca de $80 \%$ das matrículas da educação básica, atendendo em sua maioria a população de crianças e jovens carentes, que a política privatista brasileira insiste em manter excluída do processo humano-formativo escolar.

Em nosso caso, também para transformar as situações que fazem do ensino um instrumento da elite capitalista neoliberal dominante. Que o estágio transforme o ensino em condição de emancipação das crianças e jovens oprimidos socialmente por essas elites, que buscam manter essa camada da população em condição de explorados. Por isso, explicitamos que o professor que queremos formar é o profissional crítico-reflexivo, pesquisador de sua práxis docente e da práxis que ocorre nas escolas. Para isso, o estágio pode instrumentalizá-lo teoricamente para que abrace a perspectiva 
transformadora, ou seja, para que nos estágios esse futuro docente analise, compreenda, conheça, criticamente, desvele as teorias conservadoras que subjazem à práxis escolar. A pesquisa, nesse sentido, constitui-se em método que instrumentaliza essa perspectiva. Assim, formulamos a proposta de que o estágio seja realizado com e como pesquisa.

Com as análises que empreendemos neste texto, esperamos contribuir com os esforços de todos aqueles - professores das escolas e das universidades, estudantes em formação, gestores dos cursos de licenciatura - empenhados em construir políticas públicas e projetos políticos pedagógicos definidos e praticados coletivamente, políticas estas assentadas em uma perspectiva teórico-prática que instrumentalize a práxis docente e a práxis educativa das escolas; uma práxis que seja transformadora das condições precárias que marcam a formação e o exercício da profissão docente na sociedade dominada pelos agentes privatistas financistas que visam diminuir cada vez mais o profissional docente, reduzindo-o a uma condição de prático/pragmático que não precisa de teorias, dizem.

\section{REFERÊNCIAS}

BrAsIL.Edital MEC/CAPES/FNDE n. 01/2007 — para instituições federais de ensino superior (IFES). Brasília, DF: 2007.

Brasil. Portaria normativa n. 38, de 12 de dezembro de 2007. Dispõe sobre o Programa Institucional de Bolsa de Iniciação à Docência. Brasília, DF, 2007. Disponível em: <http://www.cmconsultoria.com.br/imagens/diretorios/diretorio14/arquivo1003.pdf>. Acesso em: 11 jan. 2019.

BrAsil. MEC/CAPES. Edital CAPES n. 02/2009 - para instituições federais e estaduais de ensino superior. Brasília, DF: 2009.

BrASIL. MEC/CAPES. Edital CAPES n. 18/2010 — para instituições públicas municipais e comunitárias, confessionais e filantrópicas sem fins lucrativos. Brasília, DF: 2009.

Brasil. Decreto n. 7.219, de 24 de junho de 2010. Dispõe sobre o Programa Institucional de Bolsa de Iniciação à Docência - PIBID e dá outras providências. Diário Oficial da União, Brasília, DF, 25 jun. 2010. Disponível em: <http://www.planalto.gov.br/ccivil 03/ ato2007-2010/2010/Decreto/D7219.htm>. Acesso em: 27 jun. 2016.

BRASIL. MEC/CAPES. Edital n. 66/2013 CAPES, de 6 de setembro de 2013: PIBID - Diversidade. Brasília: DF: CAPES, 2013. p. 28.

Brasil. MEC/CAPES. Edital n. 61/2013 CAPES, de 2 de agosto de 2013: para instituições públicas, comunitárias e privadas com bolsistas do ProUni. Brasilia: DF: 2013. Brasil. Portaria 096, de 18 de julho de 2013. Aperfeiçoa e atualiza as normas do PIBID. Brasília, DF, 2013. Disponível em: <http://www.capes.gov.br/images/stories/download/ legislacao/Portaria 096 18jul13 AprovaRegulamentoPIBID.pdf>. Acesso em: 11 jan. 2019

Brasil. Resolução CNE/CP n. 02/2015, de 1º de julho de 2015. Define as Diretrizes Curriculares Nacionais para a formação inicial em nível superior (cursos de licenciatura, cursos de formação pedagógica para graduados e cursos de segunda licenciatura) e para a formação continuada. Diário Oficial da União, Brasília, DF, 2 jul. 2015, p. 8-12. Seção 1. 
Capes - Coordenação de Aperfeiçoamento de Pessoal de Nível Superior. Diretoria de formação de professores da educação básica. Relatório de Gestão PIBID 20092013. Brasília, DF: 2013. Disponível em: <https:/www.capes.gov.br/images/stories/ download/bolsas/2562014-relatrorio-DEB-2013-web.pdf>. Acesso em: 10 jan. 2019. CARneiro, M. C. PIBID/UNASP - Matemática: a construção dos saberes a partir da relação teoria e prática. In: XVI Encontro Nacional de Didática e Prática de Ensino. Livro 2. Araraquara: Editora Junqueira \& Marin, 2012. p. 234-246.

Delors, J. Educação: um tesouro a descobrir. 2. ed. São Paulo: Cortez; Brasília, DF: MEC/UNESCO, 2003. (Relatório Delors).

Dias Sobrinho,J. Avaliação ética e política em função da educação como direito público ou como mercadoria? Educação Ė Sociedade, Campinas, v. 25, n. 88, p. 703-725, 2004. http://dx.doi.org/10.1590/S0101-73302004000300004

EugÊNıo, K. S. O. Estágio supervisionado na formação inicial: os laços formativos entre estágio e escola. 2015. Dissertação (Mestrado) — Programa de Pós-Graduação em Educação, Universidade Estadual do Ceará, Fortaleza, 2015.

Franco, M. A.; Pimenta, S. G. Didática multidimensional: por uma sistematização conceitual. Revista Educação E Sociedade, Campinas, v. 37, n. 135, p. 539-553, abr./jun. 2016. http://dx.doi.org/10.1590/ES0101-73302016136048

Freire, P. Pedagogia do oprimido. Rio de Janeiro: Paz e Terra, 1979.

Freire, P. Pedagogia da autonomia: saberes necessários à prática educativa. 35. ed. São Paulo: Paz e Terra, 1996.

Freitas, H. C. L. Iniciação à docência: o que temos feito? Salvador: UFBA, 2013. Apresentação realizada na Universidade Federal da Bahia, 2013.

Frigotto, G. O enfoque da dialética materialista histórica na pesquisa educacional.In: Fazenda, I.(Org.). Metodologia da pesquisa educacional. São Paulo: Cortez Editora, 1990. p. 70-90.

Ghedin, E. Professor reflexivo: da alienação da técnica à autonomia da crítica. In: Pimenta, S. G.; Ghedin, E. (Orgs.). Professor reflexivo no Brasil: gênese e crítica de um conceito. São Paulo: Cortez Editora, 2002. p. 148-173.

Ghedın, E.; Oliveira, E. S.; Almeida, W. A. Estágio com pesquisa. São Paulo: Cortez Editora 2015.

Gimenes, C. I.; Pimenta, S. G. O que dizem as publicações sobre o PIBID no Encontro Nacional de Didática e Práticas de Ensino (ENDIPE) - período 2008 a 2012? In: II Encontro Luso-Brasileiro sobre Trabalho Docente e Formação. Porto: UFAL; Red ESTRADO, 2013. p. 1-12.

Gimenes, C. I. O Programa Institucional de Bolsa de Iniciação à Docência (PIBID) e a formação de professores de ciências naturais: possibilidade para a práxis na formação inicial? 2016. Tese (Doutorado) - Faculdade de Educação da Universidade de São Paulo, São Paulo, 2016.

ineP - Instituto Nacional de Estudos e Pesquisas Educacionais Anísio Teixeira. Censo da Educação Superior: 2013. Brasília, DF: MEC; INEP, 2014.

Konder, L. O futuro da flosofia da práxis. Rio de Janeiro: Editora Paz e Terra, 1992. 
Lima, M. S. L. A prática de ensino, o estágio supervisionado, e o PIBID: perspectivas e diretrizes para os cursos de Licenciatura. In: XVI Encontro Nacional de Didática e Prática de Ensino. Araraquara: Editora Junqueira \& Marin ,2012b. p. 234-246.

NeAve, G. A privatização da educação superior e a dinâmica do Estado avaliador. In: Educação superior: questão de Estado, prioridade social. São Paulo: FNESP, 2007.

Peixoto, M. C. A avaliação institucional nas universidades federais e as comissões próprias de avaliação. Revista Avaliação da Educação Superior (Campinas), Sorocaba, v. 14, n. 1, p. 9-18, mar. 2009. http://dx.doi.org/10.1590/S1414-40772009000100002 Pimenta, S. G. O estágio na formação de professores: unidade teoria e prática? 11. ed. São Paulo: Cortez , 2012.

Pimenta, S. G; Lima, M. S. L. Estágio e docência. São Paulo: Cortez Editora, 2004.

Pimenta, S. G.; Anastasiou, L. G. C. Docência no ensino superior. São Paulo: Cortez Editora, 2002.

Pimenta, S. G. et al. Cursos de pedagogia: transgressões na formação de professores polivalentes. In: Encontro Nacional de Didática e Práticas de Ensino, 7., 2018, Salvador. Simpósio, 2018 (a ser publicado no e-book Pimenta, S. G.; D’Ávila, C. M.; Pedroso, C. C.; Mussi, A. A. (Orgs.). A didática e os desafios políticos da atualidade. Salvador: EDUFBA. 2019. p. 44-69. No prelo.

Robertson, S. L. O processo de Bolonha da Europa torna-se global: modelo, mercado, mobilidade, força intelectual ou estratégia para a construção do Estado? Revista Brasileira de Educação, Rio de Janeiro, v. 14, n. 42, p. 407-422, set./dez. 2009. http:// dx.doi.org/10.1590/S1413-24782009000300002

Romanows кi, J. P.; Martins, P. L.O. Técnicas de estudo para além da dimensão do fazer. Novas tramas para as técnicas de ensino e estudo. Campinas: Papirus, 2015.

Saviani, D. História das ideias pedagógicas no Brasil. Campinas: Autores Associados, 2008. Schneider, M. P.; Rostirola, C. G. Estado-avaliador: reflexões sobre sua evolução no Brasil. Revista Brasileira de Política e Administração da Educação, Goiânia, v. 31, n. 3, p. 493-510, set./dez. 2015. https://doi.org/10.21573/vol31n32015.63790

Sguissardi, V.Modelo de expansão da educação superior no Brasil: predomínio privado/ mercantil e desafios para a regulação e formação universitária. Educação E Sociedade, Campinas, v. 29, n. 105, p. 991-1.022, set./dez. 2008. http://dx.doi.org/10.1590/S010173302008000400004

Sguissardi, V.Educação superior no Brasil. Democratização ou massificação mercantil? Revista Educação E Sociedade, Campinas, v. 36, n. 133, p. 867-889, 2015. http://dx.doi. org/10.1590/ES0101-73302015155688

Shiroma, E. O.; Moraes, M. C. M.; Evangelista, O. Política educacional. São Paulo: DP\&A Editora, 2000.

VÁzquez, A. S. Filosofia da práxis. Rio de Janeiro: Paz e Terra ,1968.

Yannoulas, S. C; Souza, C. R. F.; Assis, S. G. Políticas educacionais e o Estado avaliador: uma relação conflitante. Sociedade em Debate, Pelotas, v. 15, n. 2, p. 57-67, jul./dez. 2009. 
Zabalza, M. A. O estágio e as práticas em contextos profissionais na formação universitária. São Paulo: Cortez , 2014.

Zeichner, K. M. Políticas de formação de professores nos Estados Unidos: como e por que elas afetam vários países no mundo. Tradução de Cristina Antunes. Belo Horizonte: Autêntica Editora, 2013.

\section{SOBRE AS AUTORAS}

Selma Garrido Pimenta é doutora em filosofia da educação pela Pontifícia Universidade Católica de São Paulo (PUC-SP). Professora da Universidade de São Paulo (USP).

E-mail: sgpiment@usp.br

Maria Socorro Lucena Lima é doutora em educação pela Universidade de São Paulo (USP). Professora da Universidade Estadual do Ceará (UECE). E-mail: socorro lucena@uol.com.br

Recebido em 26 de dezembro de 2017 Aprovado em 19 de setembro de 2018 